\title{
Eine Bemerkung \\ über den von Błażek veröffentlichten Artikel: „Ein automatischer Muskelunterbrecher". \\ Von
}

Privatdocent Dr. A. Kuliabko aus St. Petersburg.

B. B Iażek hat in diesem Archiv ${ }^{1}$ ) eine Mittheilung veröffentlicht, in der er einen von ihm construirten Muskelunterbrecher als „eine neue Methode zur Prüfung der Muskelzuckungen" beschreibt. Diese Auffassung des genannten Autors veranlasst mich, eine Bemerkung darüber zu machen, da ich selbst schon lange Zeit für die Frage über die Muskelermüdung mich interessire und eine Reihe Untersuchungen auf diesem Gebiet gemacht habe. Ich erlaube mir desswegen, auf einige Ungenauigkeiten in Blażek's Arbeit hinzuweisen.

Die Methode, welche Blażek als eine neue beschreibt, ist gar nicht neu. Sie wurde schon früher vielmals angewandt, u. A. von Wundt, Fick, Ivo Novi ${ }^{2}$ ) u. v. A.; seine Beschreibung findet man auch in einigen Hand- und Lehrbüchern, so z. B. Stewart, Manual of Physiology p. 493 Fig 146. London 1896. Wenn man diese letztere Beschreibung und Abbildung mit den von B la żek angegebenen vergleicht, so findet man, dass auch in den mechanischen Vorrichtungen der Unterschied nur darin besteht, dass Blażek seinen Unterbrechungsstift an der Seite des Schreibhebels angebracht hat. Seine auf Seite 531 abgebildete Curve ist der von Ivo Novi (1. c.) gegebenen sehr ähnlich.

Bei meinen Versuchen branchte ich auch ähnliche Vorrichtungen mit einigen Veränderungen, von welchen ich etwas genauer sprechen möchte. Die Schliessung des primären Stromes vollzieht sich bei mir vermittelst eines am Schreibhebel befestigten Platinstiftes und

1) Siehe Pflüger's Arch. f. d. ges. Physiol. Bd. 85 H. 11/12 S. 529-585. 1901.

2) Die grapbische Darstellung der Muslrelermüdung. Centralbl. f. Physiol. Bd. 11 S. 377-381. 1897. 
einer darunter liegenden Platinspitze, welche durch eine feine Schraube sich heben und senken lässt und zugleich als eine die Ausdehnung des Muskels in Ruhe verhindernde Unterlage dient (Nachbelastungsverfahren). Bei der Berührung der Contacte im Apparate von Blazek, sowie auch bei Ivo Novi schliesst sich der primäre Strom und gleichzeitig entsteht ein Schliessungsschlag; welcher auf den Muskel wirkt und denselben zur Contraction bringt. Der Muskel zuckt und unterbricht sofort den primären Kettenstrom. Dadurch entsteht ein Oeffnungsinductionsschlag, welcher den Muskel am Anfang seiner Zusammenziehung beeinflusst; der Muskel erhält also z wei nach einander folgende Inductionsschläge, und seine Contraction ist ein Resultat des summirten Reizes. Diesen Umstand muss man bei genauen Untersuchungen nicht vernachlässigen. Aus den bekannten Untersuchungen von v. Frey u. A. wissen wir, dass, die Effecte der summirten Reizung immer verschieden sind; je nach der Dauer der Pause zwischen zwei nach einander folgenden Reizen bei derselben Stärke beider Reizungen können wir ganz verschiedene zusammengesetzte Zuckungen bekommen, wenn wir nur die Zwischenzeit verändern. Nun, muss man bei dem Ermüdungsstudium nicht auf den absoluten Werth dieser Pause, sondern auf die Beziehung derselben zur gesammten Zuckungsperiode achten, welche beim Auftreten der Ermüdung gerade sehr veränderlich ist. Die Dauer der Reizintervalle, welche bei kurzer Periode des schnell zuckenden unermüdeten Muskels eine Verstärkung der Zuckungshöhe beeinflussen, kann bei verlängerten Contractionen des ermüdeten Muskels zu einem gerade entgegengesetzten Effecte führen. Bei Summirung der Reize von verschiedener Stärke werden natürlich die Bedingungen noch viel complicirter.

Bei meinen Untersuchungen habe ich die Apparate so angeordnet, dass bei Berührung des Platinstiftes mit der Platinspitze die Stromschliessung nicht in der primären Inductionskette entstand, sondern in einem Relais; dasselbe unterbricht die primäre Stromkette und der in der secundären Spirale entstehende Oeffnungsschlag gelangt zum Präparate. Beim Anfang der Zuckung unterbricht der Muskel den Relais-Strom, und zugleich unterbricht er vermittelst einer besonderen Contactvorrichtung auch die Bahn, durch welche der Inductionsschlag zum Präparate gelangen kann; dadurch wird die Wirkung des Schliessungsseblages beseitigt. - Von meinen bisherigen Resultaten, welche ich in kurzer Zeit zu veröffentlichen 
hoffe, möchte ich hier nur erwähnen, dass meine Ermüdungscurven von denjenigen der Herren I vo Novi und Blażek sich hauptsächlich dadurch unterscheiden, dass man an ihnen noch eine besondere Anfangsperiode mit auffallend langsam dauernden Zuckungen beobachten kann, - die Erscheinung, auf welche schon Mosso aufmerksam macht. Diese Verlangsamung der ersten Zuckungen ist hauptsächlich an der zweiten (absteigenden) Hälfte des Myogramms bemerkbar. Indem diese anfänglichen Zuckungen sich allmälig beschleunigen, kommt die zweite Periode mit normaler Zuckungsdauer und mehr und mehr abnehmender Zuckungshöhe, dann eine deutliche Verlangsamung mit bedentender Zunabme der Höhe; weiter folgt eine neue Abnahme bei fortdauernder Verlangsamung und endlich eine Periode von sehr schwachen, aber kurzdauernden Zuckungen. Ich unterscheide also in Uebereinstimmung mit den Angaben von Ivo Novi im Allgemeinen fünf Zuckungsperioden und füge noch eine sechste Anfangsperiode hinzu. Auf weitere, eingehende Angaben muss ich leider verzichten, da meine Untersuchungen, welche bauptsächlich die Wirkung der Abkühlung und Erwärmung auf die Ermüdungsvorgänge betreffen, noch nicht geschlossen sind. 